\section{The effectiveness of hydrogen peroxide liquid or gas plasma on protozoan oocysts}

To the Editor:

Gastroendoscopy is increasingly in demand to diagnose and treat illnesses of the gastrointestinal tract. Because endoscopes may become contaminated with infectious agents from the intestine or rectum, they have to be reprocessed. The infectious agents that are most difficult to destroy (second to prions) are the oocysts of coccidian parasites such as Cryptosporidium and Cyclospora $(1,2)$. No liquid disinfectants, including the much-studied aldehydes, have been shown to be entirely effective. We used hydrogen peroxide, a newer oxygenated product to the market, in both liquid and gaseous form, in a bioassay to test its effectiveness in inactivating oocysts. Because human coccidial parasites, such as Cryptosporidium, are hazardous to handle in the laboratory, we used a close alternative, Eimeria aceruulina, as a surrogate (3). This parasite causes coccidiosis in chickens. In this bioassay, if oocysts are inactivated, they will not produce evidence of infection, lesions or replicate themselves to produce oocysts in chickens.

Our studies confirmed that despite a $3 \mathrm{~h}$ soak in any of the hydrogen peroxide liquid disinfectants, some oocysts remained infectious (Table 1). In contrast to liquid disinfectants, a

TABLE 1

Effect of hydrogen peroxide disinfectants on sporulated Eimeria acervulina oocysts after a $3 \mathrm{~h}$ soak. Inocula between 10,000 and 15,000 oocysts were given orally to each chick on the first or second day of hatch

\begin{tabular}{|c|c|c|c|c|c|}
\hline \multirow[b]{2}{*}{ Treatments } & \multicolumn{2}{|c|}{ Trial 1} & \multicolumn{2}{|c|}{ Trial 2} & \multirow{2}{*}{$\begin{array}{c}\text { Total } \\
\text { positive }\end{array}$} \\
\hline & Lesions & Oocysts & Lesions & Oocysts & \\
\hline No treatment & $5 / 5$ & - & $5 / 5$ & - & $10 / 10$ \\
\hline $\begin{array}{l}25 \% \text { hydrogen peroxide, } \\
5 \% \text { peracetic acid }\end{array}$ & $5 / 5$ & - & $9 / 9$ & $3 / 3^{*}$ & $14 / 14$ \\
\hline $\begin{array}{c}2.5 \% \text { hydrogen peroxide, } \\
0.5 \% \text { peracetic acid }\end{array}$ & $5 / 5$ & - & $5 / 5$ & - & $10 / 10$ \\
\hline $7.5 \%$ hydrogen peroxide & $5 / 5$ & - & $5 / 5$ & - & $10 / 10$ \\
\hline $\begin{array}{l}2 \% \text { hydrogen peroxide } \\
\quad \text { (product } A)\end{array}$ & $5 / 5$ & - & $5 / 5$ & - & $10 / 10$ \\
\hline $\begin{array}{l}2 \% \text { hydrogen peroxide } \\
\quad \text { (product B) }\end{array}$ & $5 / 5$ & - & $5 / 5$ & - & $10 / 10$ \\
\hline Heat-treated controls & $0 / 3$ & $0 / 2$ & $0 / 5$ & $0 / 5$ & $0 / 15$ \\
\hline
\end{tabular}

${ }^{*}$ Fecal collections of three chicks before necropsy showed an abundance of oocysts. Five of five means that five birds produced evidence of infection, either lesions or oocysts, out of five birds that were inoculated. Likewise, zero of five means that no birds produced evidence of infection, neither lesions nor oocysts, out of five birds that were inoculated hydrogen peroxide gas plasma system, operating at less than $50^{\circ} \mathrm{C}$, inactivated all E acervulina oocysts (Table 2) from the surface (aluminum foil) and from the inside of narrow tubing (inner diameter of $3 \mathrm{~mm}$ ). None of the 40 chicks inoculated with gas plasma-treated oocysts produced lesions ( $\mathrm{n}=15$ chicks inoculated) or oocysts ( $n=25$ chicks inoculated). Oocysts that were either airdried on aluminum foil or inside narrow tubing, but not treated with gas plasma, remained infectious for all chicks $(n=25)$. Heattreated controls did not produce infection.

These results were similar to the study by Vassal et al (4), in which $10^{5}$ Cryptosporidium paruum oocysts treated in a $75 \mathrm{~min}$ cycle, hydrogen peroxide gas plasma system (STERRAD 100s [Advanced Sterilization Products, USA]), were found to be noninfectious to immunocompromised Sprague-Dawley rats. This similarity in behaviour between E acervulina oocysts and Cryptosporidum oocysts in their response to hydrogen peroxide also supports the usefulness of E acervulina as a surrogate for testing the sterilization of endoscopes. In addition, E acervulina oocysts are safe and economical to handle and provide verifiable and clear evidence of inactivation.

ACKNOWLEDGEMENTS: The authors gratefully acknowledge the contributions of Ms Wenrong Sun for assisting with the microbiological tests, Ms Alyssia Greig for laboratory technical assistance and Ms Vreni Lall for her help with the STERRAD $100 \mathrm{~S}$ portion of the present study.

The present project was approved by the Animal Care Committee at Ryerson University (Toronto, Ontario). No funding was received from the manufacturers or distributors of any of the products used in the study.

MB Lee ScM CPHI(C)

School of Occupational and Public Health, Ryerson University, Toronto, Ontario

EH Lee PhD

Vetech Laboratories Inc, Guelph, Ontario

\section{REFERENCES}

1. Wilson JA, Margolin AB. The efficacy of three common hospital liquid germicides to inactivate Cryptosporidium parvum oocysts. J Hosp Infect 1999;42:231-7.

2. Quinn PJ, Markey BK. Disinfection and disease prevention in veterinary medicine. In: Block S, ed. Disinfection, Sterilization, and Prevention, 5th edn. Philadelphia: Lippincott Williams \& Wilkins; 2000:1069-103.

3. Lee MB, Lee EH. Coccidial contamination of raspberries: Mock contamination with Eimeria acervulina as a model for decontamination treatment studies. J Food Prot 2001;64:1854-7.

4. Vassal S, Favennec L, Ballet JJ, Brasseur P. Hydrogen peroxide gas plasma sterilization is effective against Cryptosporidium parvum oocysts. Am J Infect Control 1998;26:136-8.

TABLE 2

Infectivity of sporulated Eimeria acervulina oocysts treated by a hydrogen peroxide gas plasma system*. Inocula between 2000 and 20,000 oocysts were given orally to each chick on the first or second day of hatch

\begin{tabular}{|c|c|c|c|c|c|c|c|}
\hline \multirow[b]{3}{*}{ Treatment } & \multicolumn{4}{|c|}{ Preparation 1} & \multicolumn{2}{|c|}{ Preparation 2} & \multirow{3}{*}{$\begin{array}{c}\text { Total } \\
\text { positive }\end{array}$} \\
\hline & \multicolumn{2}{|c|}{ Sample 1} & \multicolumn{2}{|c|}{ Sample 2} & \multirow{2}{*}{$\begin{array}{c}\text { Sample } 1 \\
\text { Oocysts }\end{array}$} & \multirow{2}{*}{$\begin{array}{l}\text { Sample } 2 \\
\text { Oocysts }\end{array}$} & \\
\hline & Lesions & Oocysts & Lesions & Oocysts & & & \\
\hline Untreated controls (oocyst culture) & ND & ND & $5 / 5$ & $5 / 5$ & $5 / 5$ & $5 / 5$ & $20 / 20$ \\
\hline Untreated controls (oocysts on aluminum foil, air-dried only) & $5 / 5$ & ND & $5 / 5$ & $5 / 5$ & ND & ND & $15 / 15$ \\
\hline Hydrogen peroxide gas plasma (oocysts on aluminum foil) & $0 / 10$ & $0 / 5$ & $0 / 5$ & $0 / 5$ & ND & ND & $0 / 25$ \\
\hline Untreated controls (oocysts in tubing, air-dried only) & ND & ND & ND & ND & $5 / 5$ & $5 / 5$ & $10 / 10$ \\
\hline Hydrogen peroxide gas plasma (oocysts in tubing) & ND & ND & ND & ND & $0 / 5$ & $0 / 10$ & $0 / 15$ \\
\hline Heated controls & $0 / 5$ & ND & $0 / 5$ & $0 / 5$ & $0 / 5$ & $0 / 5$ & $0 / 25$ \\
\hline
\end{tabular}

*STERRAD 100s (Advanced Sterilization Products, USA). ND Not determined 


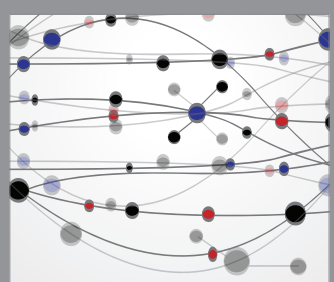

The Scientific World Journal
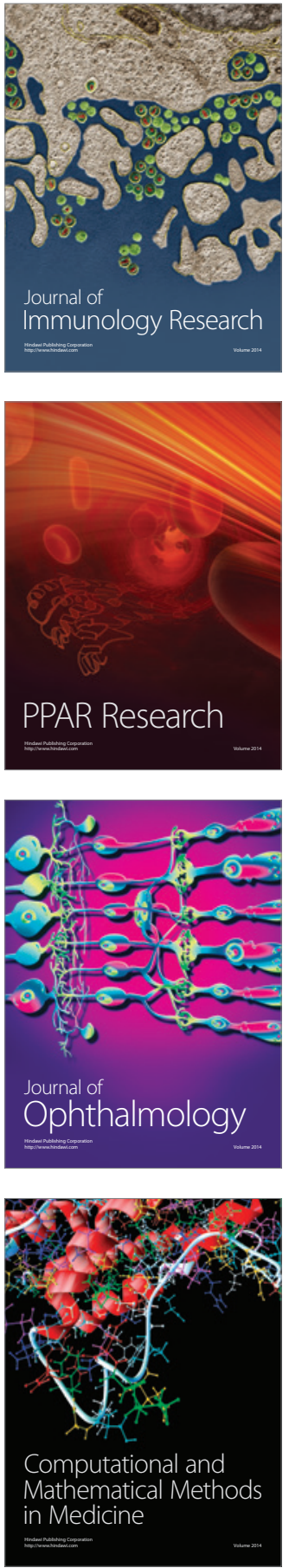

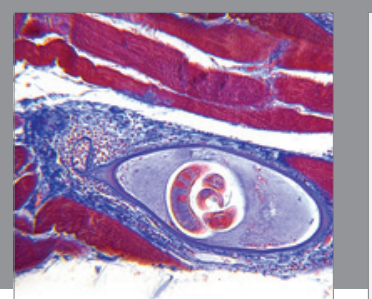

Gastroenterology Research and Practice

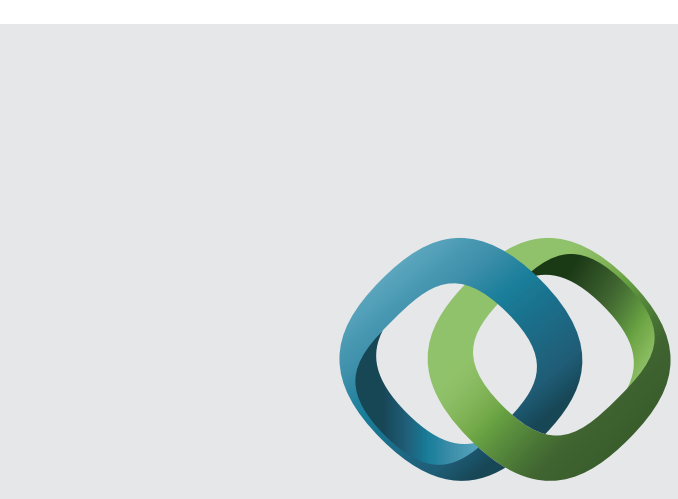

\section{Hindawi}

Submit your manuscripts at

http://www.hindawi.com
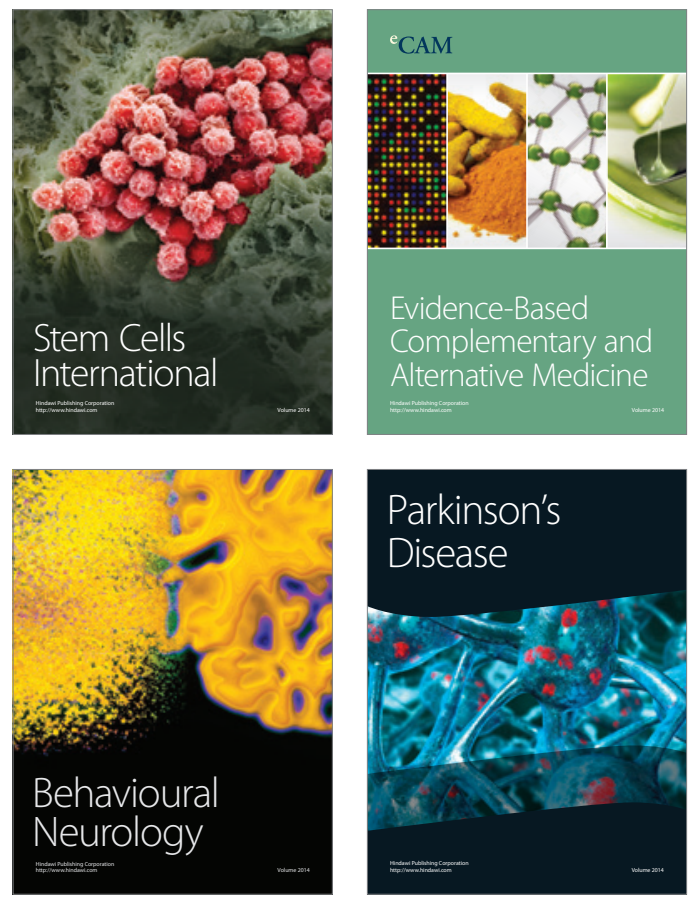
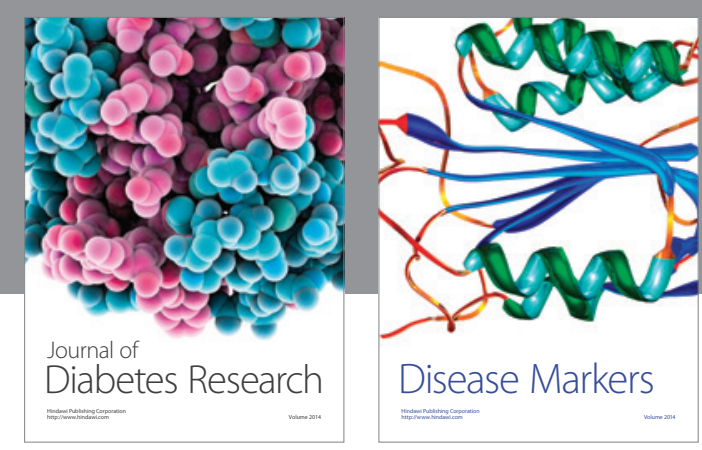

Disease Markers
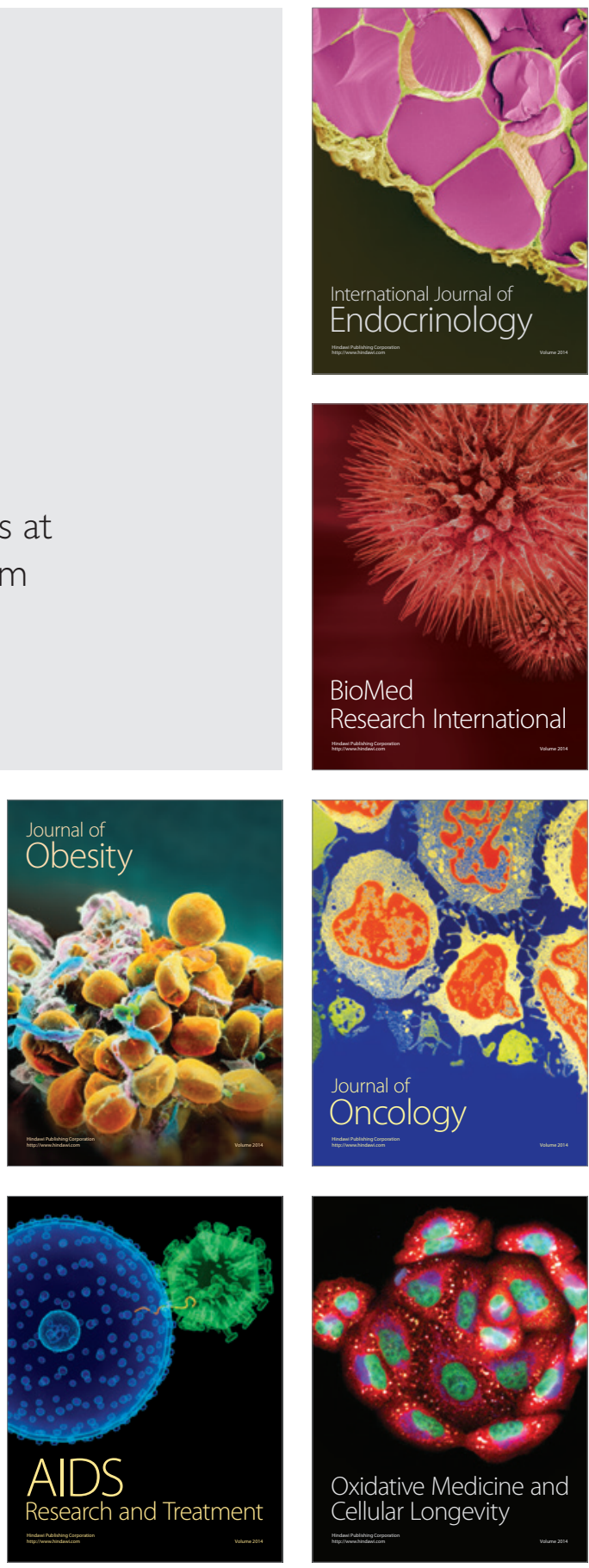